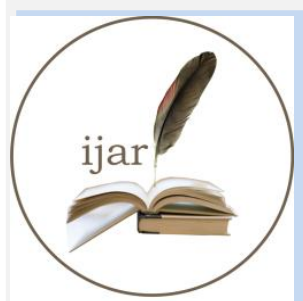

ISSN NO. 2320-5407
Journal Homepage: $-\underline{w w}$.journalijar.com
INTERNATIONAL JOURNAL OF
ADVANCED RESEARCH (IJAR)

Article DOI: $10.21474 / \mathrm{IJAR} 01 / 1309$

DOI URL: http://dx.doi.org/10.21474/IJAR01/1309
INTERNATIONAL JOURNAL OF ADVANCED RESEARCH (JSAR)

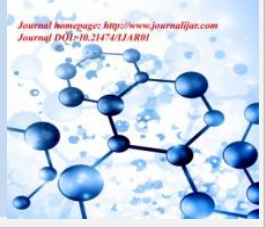

RESEARCH ARTICLE

\title{
ANALYSIS OF PATIENT WAITING TIME FOR HOSPITAL ADMISSION AND DISCHARGE PROCESS.
}

\author{
Dr. Niloy Sarkar ${ }^{1}$ and Ms. Tatini Nath ${ }^{2 *}$
}

1. Professor and Dean - Academics, NSHM College of Management and Technology, Durgapur.

2. Junior Executive - Operations, The Mission Hospital, Durgapur.

\section{Manuscript Info}

Manuscript History

Received: 11 June 2016

Final Accepted: 12 July 2016

Published: August 2016

Key words:-

Waiting Time, Admission Process,

Discharge Process, Spot Discharge,

Planned Discharge

\section{Abstract}

Waiting time for hospital admission and discharge process is a common problem existing in all the hospitals, whether it is a small or a big setup. The main objective of the study is to identify the gaps, highlight those areas where delay can be eliminated and recommend accordingly, so that the hospital admission and discharge process can be managed smoothly. This paper has explained both the hospital admission and discharge process in a simple way and has tried to find out the root causes for the delay in discharge process. This paper concludes with a list of suggestions. The set-up of the study was Apollo Hospitals, Greams Lane, Chennai (15 ${ }^{\text {th }}$ June $-14^{\text {th }}$ August, 2012).

Copy Right, IJAR, 2016,. All rights reserved.

\section{Introduction:-}

Long waiting time in a hospital is considered as an indicator of poor quality and so it needs improvement. Managing waiting lines creates a great dilemma for managers, seeking to improve the return on investment of their operations. On the one hand, customers dislike waiting intensely. If they feel they are waiting too long at hospital for receiving service, they will either leave the line prematurely or not return back to the hospital for the next time when they are in need of seeking service. This will reduce customer demand and eventually revenue \& profit.

Long waiting time creates frustration for patients and attains lower satisfaction scores. The Emergency Department is now the "front door" of the hospital, where patients first enter. A busy, overflowing Emergency Department is no longer an indication of profitability. Overcrowding in the Emergency Department may seem to be an obvious link to increase the waiting time, it is possible to accommodate growing volume if we can decrease the waiting time.

Delayed discharge or 'bed blocking' are terms used to describe the inappropriate occupancy of hospital beds. Delay in discharging of patients from hospital is a long-standing and common problem. Delayed discharges have an impact on hospitals' ability to cut waiting lists and deliver healthcare effectively and efficiently.

The aim of this study was to analyze the causes of delay in hospital admission and discharge for patients admitted.

\section{Methodology:-}

The flow of study is:

1. Case based time and motion study of the existing process

2. Analysis of the data supported by various statistical methods 


\section{Objectives:-}

- To map the admission and discharge process in words

- Identify gaps and grey areas in the admission and discharge process

- To determine the main steps where possible delay can be eliminated

- To recommend different ways to reduce the waiting time.

\section{Major Findings:-}

Case Based Time and Motion Study of the Existing Process:-

A time and motion study is a business efficiency technique and is a major part of scientific management. It is a direct and continuous observation of a task, using a timekeeping device. A process map was plotted, for further systematic move. The total sample size was 200. Each patient was traced step by step and the time was noted for each step in a proper line with the process map developed. A format was developed to conduct the time and motion study. The tool used for developing the format and entering the data was Microsoft Excel 2011.

\section{Analysis of the data:-}

Admission Process:-

Data was divided into Cash and Non-Cash Patients (involves TPA and Credit Companies) and under each type, the patients were further classified into Walk-in and Booked Patient.

The minimum time taken to complete the entire process was considered as the "ideal time" and any deviation from the ideal time was considered to be a delay.

\section{Discharge Process:-}

Data was divided into Cash and Non-Cash Patients (involves TPA and Credit Companies) and under each type, the patients were further classified into Planned and Spot Discharge Patients.

Any planned discharge taking place after $11 \mathrm{am}$ and any spot discharge taking place after $2 \mathrm{pm}$ was considered to be a deviation leading to delay.

The data was analyzed to interpret the relation and correlate the cause and effect of various factors that could be the reasons for delay in the process:

- Correlation between overall delay in admission and overall delay in discharge process

- Identification of various reasons for delay in discharge process in order to identify the cause and effect.

- Fishbone diagram to represent the cause and effect analysis

\section{Regression and Correlation:-}

They are the tools, which may be used to test the statistical significance of association. Correlation is a measure of association between two variables.

The value of a correlation coefficient can vary from minus one to plus one. A minus one indicates a perfect negative correlation, while a plus one indicates a perfect positive correlation. A correlation of zero means there is no relationship between the two variables. When there is a negative correlation between two variables, as the value of one variable increases the value of the other variable decreases, and vice versa. In other words, for a negative correlation, the variables work opposite each other. When there is a positive correlation between two variables, as the value of one variable increases, the value of the other variable also increases. The variables move together.

The standard error of a correlation coefficient is used to determine the confidence intervals around a true correlation of zero. If your correlation coefficient falls outside of this range, then it is significantly different than zero. The standard error can be calculated for interval or ratio-type data. Simple regression is used to examine the relationship between one dependent and one independent variable. After performing an analysis, the regression statistics can be used to predict the dependent variable when the independent variable is known. Regression goes beyond correlation by adding prediction capabilities. The regression line (known as the least squares line) is a plot of the expected value of the dependent variable for all values of the independent variable. Technically, it is the line that "minimizes the squared residuals". The regression line is the one that best fits the data on a scatter plot. 


\section{Current Discharge Situation:-}

First we will try to find out what the current situation is i.e. we will try to find out how much percentage of discharges are occurring within time. If the process of planned discharge is completed by 11:00 AM then it comes under "No Delay" category. Similarly if the process of spot discharge is completed by 2:00 PM then it is also a "No Delay" case. The following graphs show the current scenario:

TABLE: 1 - Bar diagram showing the percentage of "No delay" in case of Total discharges:

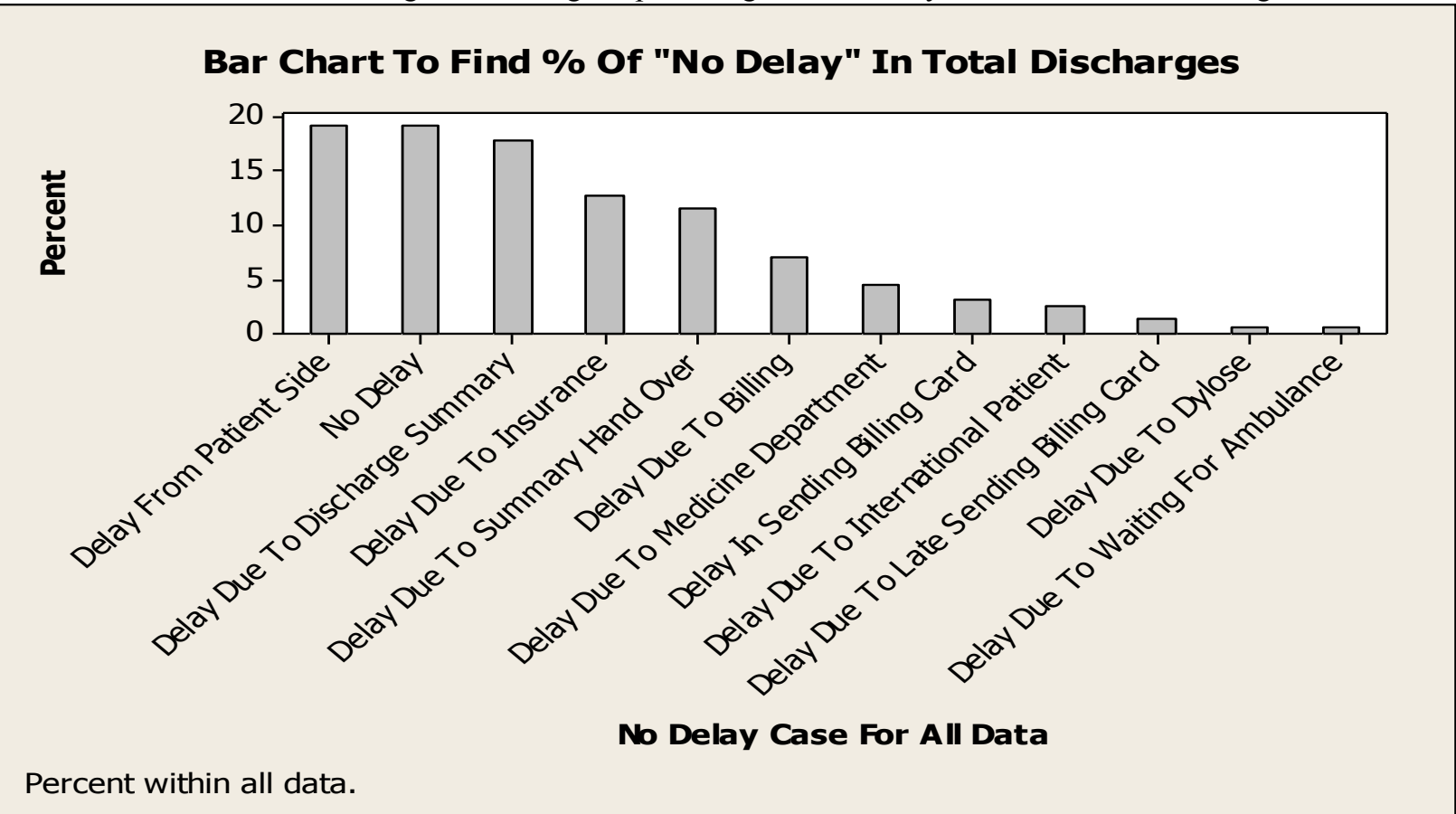

TABLE: 2 - Bar diagram showing the percentage of "No delay" in case of Spot discharges:

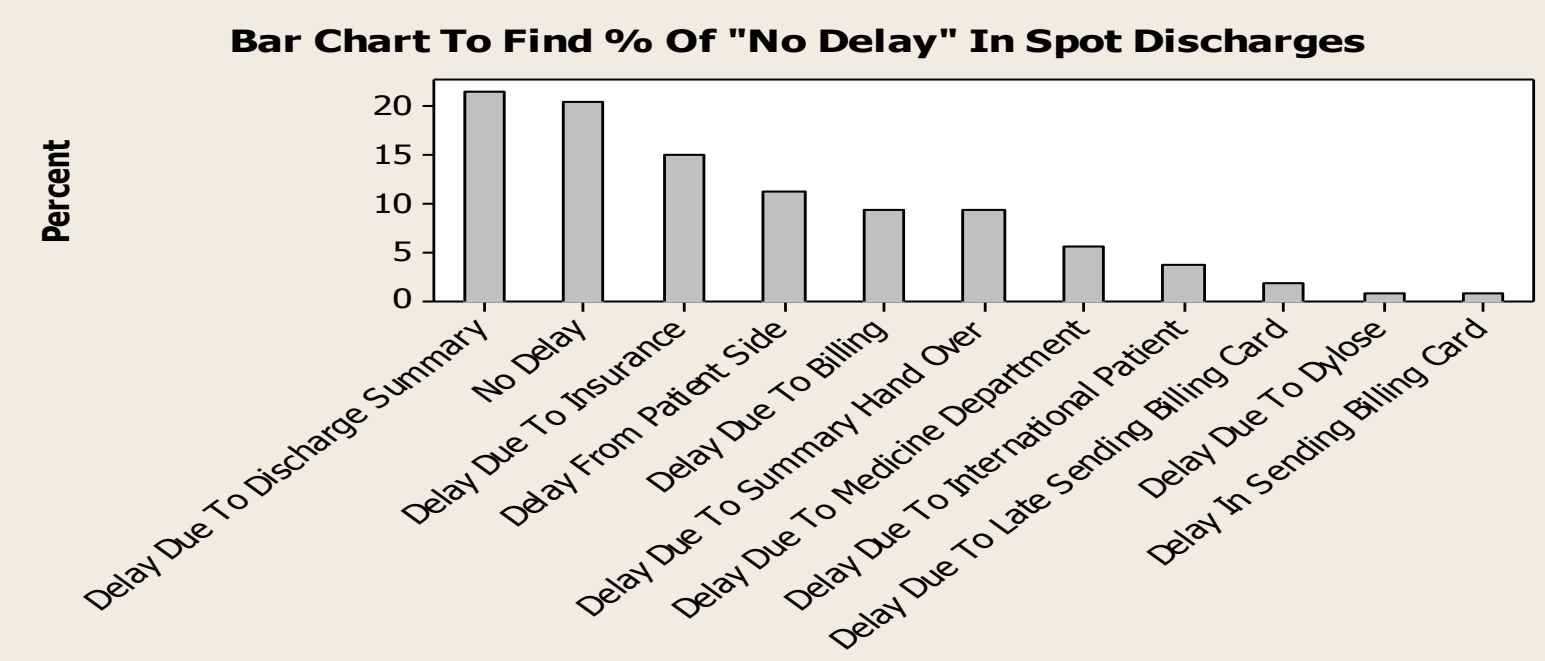

Percent within all data. 
TABLE: 3 - Bar diagram showing the percentage of "No delay" in case of Planned discharges:

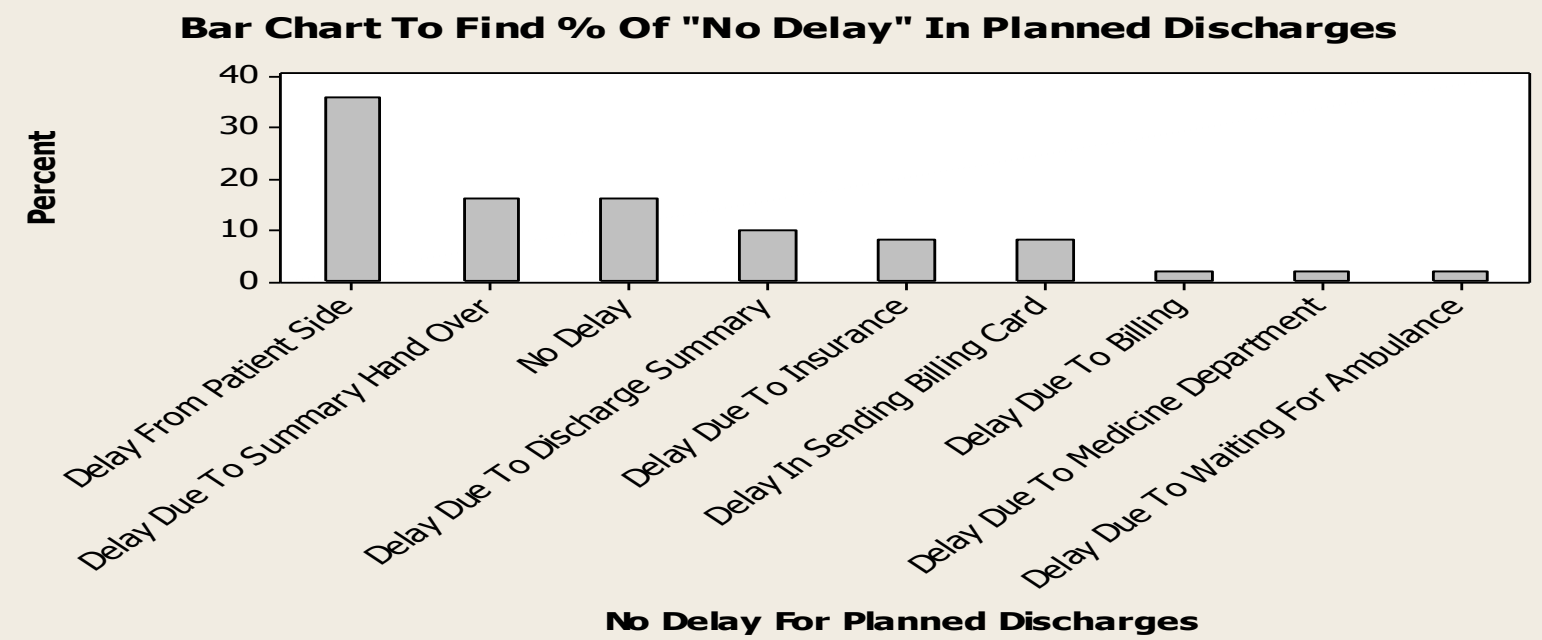

Percent within all data.

From Table- 1 we can note that only $20 \%$ discharges are occurring within time. If we look on second graph, i.e. Table- 2 it also shows that only $20 \%$ spot discharges are occurring within time and only $18 \%$ planned discharges are occurring within time. Therefore we are facing lots of problem due to these delays. Many new patients are waiting outside for the rooms to get vacate. Now we will try to find out the root causes for these delays.

\section{Results and discussion:-}

Arrival of Patient:-

1. Patient arriving for $\mathrm{OPD} / \mathrm{MHC}$ are registered and provided with an UHID number. Old patients need not register.

2. They can directly take appointment, meet the consultant and get the required investigations done.

3. After consulting the doctor with the post investigation reports, they either go home or get an admission done as per the consultant's advice.

4. The consultant gives an admission slip, which is mandatory for getting admission as inpatient and also to carry forward with the immediate proceeding once the patient is shifted in the ward after getting admitted.

5. The slip contains the following information:

- $\quad$ Patients Name and UHID

- Doctors Name

- Reason for Admission

- Estimated Cost for Procedure

- Approximate Length Of Stay

6. The patient then goes to Admissions Department.

\section{Admissions Department:-}

1. The patient comes in with their relative and contacts to the admission desk with the admission slip and blue file.

2. The patient's details are filled in by the staff into Wipro System

3. Choice of room type is suggested by patient/patients' relative and availability is checked for the same.

4. The choice of room may be based on tariff, patient requirements or allowance by insurance or corporate.

5. In case the patient has insurance then they have to approach the insurance desk for required clearance paper. Similarly a corporate patient has to approach the corporate desk for clearance paper.

6. Incase opted room category is not available than the patient has to wait or is given a general ward room and on availability of the opted room category the shifting is made afterwards.

7. The patient signs a consent form.

8. An admission folder is comprised of printed admission paper filled with patient details; admission slip, admission band, attendant and reliever pass and deposit slip. Patient or patient relative is then sent to billing desk. 


\section{Billing:-}

1. The patient relative takes this form to the billing section and pays the required deposit amount. In case of insurance/corporate patient approved by the concerned organization, no such procedure is applicable.

2. The patient is then given a wrist band indicating the UHID of the patient and name of the patient.

3. The patient is then taken to the allotted ward by the GDA of the Admissions Department

Meanwhile the housekeeping and Nurse of the allotted ward are informed so as to make the required arrangements.

\section{Data Collection:-}

A brainstorming session was conducted to identify the potential factors influencing the delay. Based on the brainstorming session results, it was decided to collect data on the following attributes namely, discharge confirmation time, billing card send time, final bill prepared time, patient settling bill time, discharge summary ready time and patient vacating time.

\section{Data Analysis:-}

TABLE: 4 - Graphical Representation of the Delay in Admission Process:

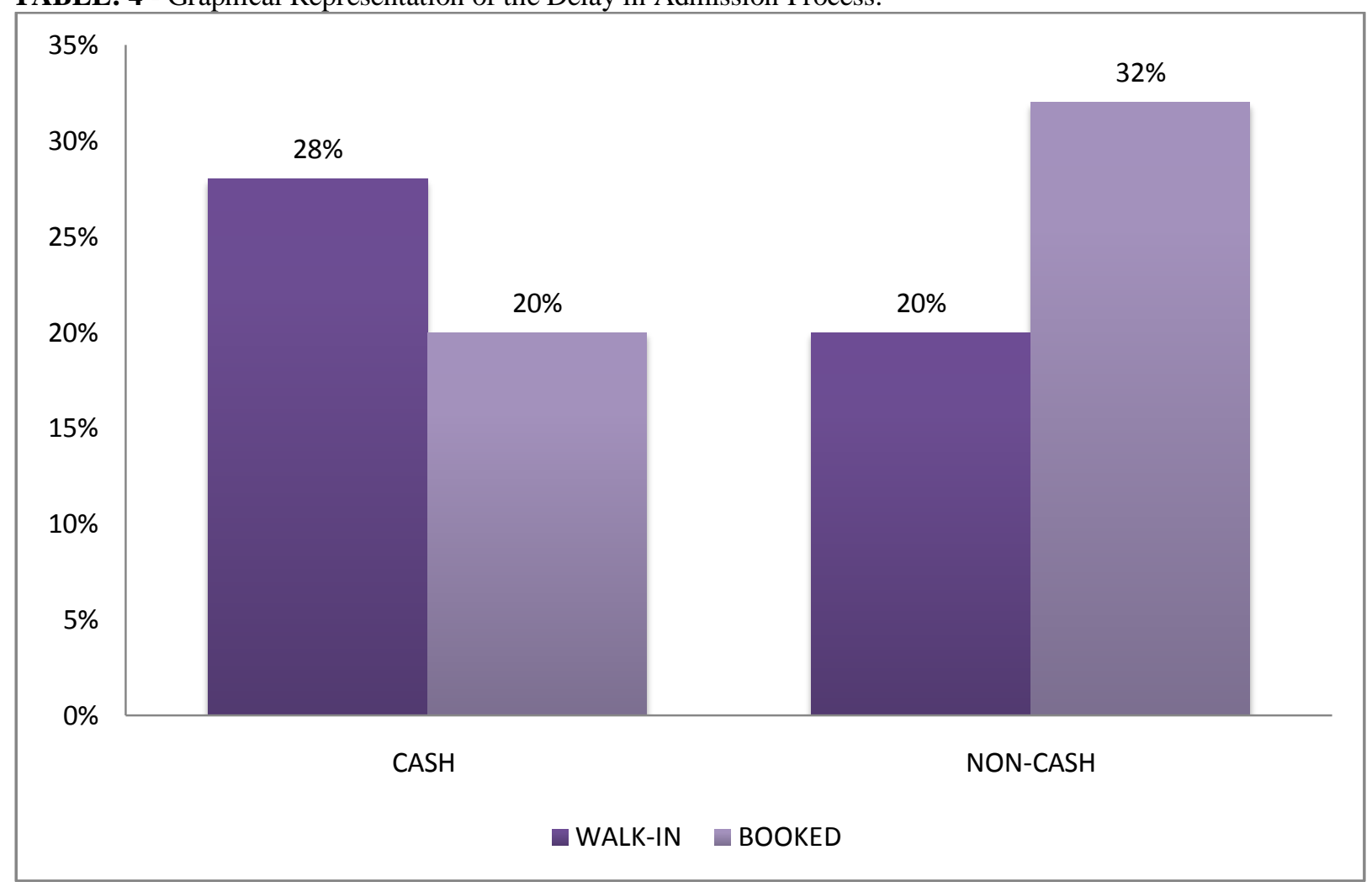

\section{Analysis:}

The average time taken for admission is compared between Booked and Walk-in patients for Cash and Non Cash Patients:

The delay in admission process for patients whose mode of payment is by Cash -2 hours and 25minutes The delay in admission process for patients whose mode of payment is either insurance or credit -4 hours and 15minutes. Five important areas of analysis was consolidated from the entire discharge process and further analyzed. These five parameters that greatly influence the Discharge process are:
A. Time Taken at Admission Counter
B. Time Taken for Insurance
C. Time Taken at Cash Counter
D. Time Taken for Bed Allotment
E. Waiting Time for Miscellaneous Reason 


\section{Regression and Correlation:-}

Using SPSS software, the R-squared value was determined. The $\mathrm{R}$ - squared value determines the percentage significance of a factor in determining the overall time taken in the process. The delay in each step of the process was calculated. The regression correlation analysis was applied to identify the percentage significance in determining the overall delay in the admission process.

Factors attributing to the Overall Time Taken and Delay in Admission Process:

\begin{tabular}{|l|l|r|r|}
\hline S. No & \multicolumn{1}{|c|}{ Steps in admission process } & $\begin{array}{c}\text { \% Significance in } \\
\text { determining overall time taken } \\
\text { for the admission process }\end{array}$ & $\begin{array}{c}\text { \% Significance in } \\
\text { determining overall delay in } \\
\text { admission process }\end{array}$ \\
\hline A & Time Taken at Admission Counter & 3.3 & 2.8 \\
\hline B & Time Taken for Insurance & 32.4 & 28.1 \\
\hline C & Time Taken at Cash Counter & 2.1 & 1.7 \\
\hline D & Time Taken for Bed Allotment & 56.4 & 62.2 \\
\hline E & Waiting Time for Miscellaneous & 5.7 & 5.2 \\
& Reasons & & \\
\hline
\end{tabular}

From the above result the following can be determined:

- Time taken to get insurance approval contributes $32.4 \%$ to the overall time taken in admission process and $28.1 \%$ to the overall delay in admission process.

- This delay is due to the time taken by the TPA or Insurance Company to approve any insurance claim. This process is independent of hospital administration process. However, patients still express dissatisfaction due to delay caused by insurance. Currently, the Apollo admits insurance patients without approval by collecting a refundable deposit from the patient.

- Time taken for bed allotment contributes $56.4 \%$ to the overall time taken in admission process and $62.2 \%$ to the overall time taken in delay at admission process.

- This delay can be addressed to non-availability of bed as per patient's requirement. This integrates the admission and discharge process and requires detailed analysis of discharge process to improve bed management.

- Reasons for miscellaneous delay do not contribute much to the overall delay but are minor irritants which affect patient satisfaction. These reasons include:

- Patient's blue file has to be transferred from OPD to Admissions; occasionally delay in arrival of blue file has been noted and subsequent delay in admissions. This is a common problem faced by staff at admission desk.

- Communication and language problems are a major drawback in quick and efficient administration of admission process.

\section{Discharge process:-}

The Discharge Process starts when the Doctor confirms about the patient discharge, ends when patient vacates the room. There are various steps involved in discharging a patient.

\section{Doctor's confirmation:}

The first step of discharging procedure is that the Doctor comes to ward. He examines patient condition and confirms about the discharge. He directs the nurse to start with the discharge process and get ready with the discharge summary. Discharge summary contains all the information about the patient, like patient's illness history, Diagnosis, medicine to be taken after discharge \& next appointment time etc. Then ward secretary informs the Jr. Doctor to write the rough summary.

\section{Rough summary typing:-}

The Jr. Doctor prepares the rough summary and gives it to the ward secretary. Ward secretary sends the rough summary for rough typing. Rough summary is typed by the typist and send back to ward. Ward secretary receives the rough summary and forward it to the Jr. Doctor for making necessary corrections. The Jr. Doctor checks the rough summary and makes the necessary corrections if required. 
Fair summary typing:-

After getting the Rough Summary corrected by Jr. Doctor, Ward Secretary sends the Rough Summary for fair typing. The typing pool types the Fair Summary and sends it to the respective ward. The Transporter Boy takes this Fair Summary from ward to the Consultant. The Consultant checks the Fair Summary. Consultant can make some more corrections if required. After reading the full summary the Consultant signs on the summary. The Transporter boy again brings the fair summary to ward and hand it over to the Ward Secretary

\section{Billing preparation process:-}

On the other hand, when the Consultant confirms about the discharge, Ward Secretary refunds the remaining extra medicines indented for the patient to pharmacy department. She updated the billing card, and mentions the order number along with the test conducted during the hospital stay of the patient, consultant's fees etc. signs on it and sends it to billing department. Billing department receives the bill. Billing Assistant checks the bill and if there is any doubt, he cross-check it with the Ward Secretary. Assistant prepares the final bill and discharge intimation. One person from billing department informs the patient's relative. He requests the Patient relative to pay the bill. After reporting to the billing desk, patient relative pays the bill (either by cash or insurance). The billing department issue two discharge intimation slip and hand it over to the patient relative.

\section{Summary hand over:-}

The patient relative brings the discharge intimations to ward. He submits both the discharge intimation to Ward Secretary. The Ward Secretary signs on both copies of discharge intimation. She keeps one copy with herself and returns the other copy to patient relative. After that Ward Secretary/Nurse hand-over and explain the final discharge summary to the patient or patient relative. Patient takes the summary along with all the reports and vacates the room.

Bottleneck in the Discharge Process:-

\begin{tabular}{|c|c|c|}
\hline Sl. No. & BOTTLE NECK & ROOT CAUSE \\
\hline 1 & $\begin{array}{l}\text { Delay in start of } \\
\text { discharge process }\end{array}$ & $\begin{array}{l}\text { Care plans with the expected length of stay and discharge date can't be created at } \\
\text { the time of admission. The discharge process starts unpredictably only when the } \\
\text { consultant examines the patient and advice the patient to get discharge during } \\
\text { rounds }\end{array}$ \\
\hline 2 & $\begin{array}{l}\text { Delay in } \\
\text { completion of } \\
\text { discharge summary }\end{array}$ & $\begin{array}{l}\text { Summaries are handwritten first and activity begins only after consultant } \\
\text { announces discharge of the patient }\end{array}$ \\
\hline 3 & $\begin{array}{l}\text { Delay in } \\
\text { preparation of final } \\
\text { bill }\end{array}$ & $\begin{array}{l}\text { Ward in-charge waits to accumulate a stack of billing files before sending them to } \\
\text { the billing counter for processing }\end{array}$ \\
\hline 4 & $\begin{array}{l}\text { Delay in financial } \\
\text { clearance }\end{array}$ & $\begin{array}{l}\text { Attendants are not immediately informed after getting ready with the final bill. } \\
\text { Late entry of charges led to a substantial hike between the interim and final bill, } \\
\text { this point was often questioned during settlement. }\end{array}$ \\
\hline
\end{tabular}


Data Analysis:-

TABLE: 5 - Summary of Data Collected for Discharge Process:-

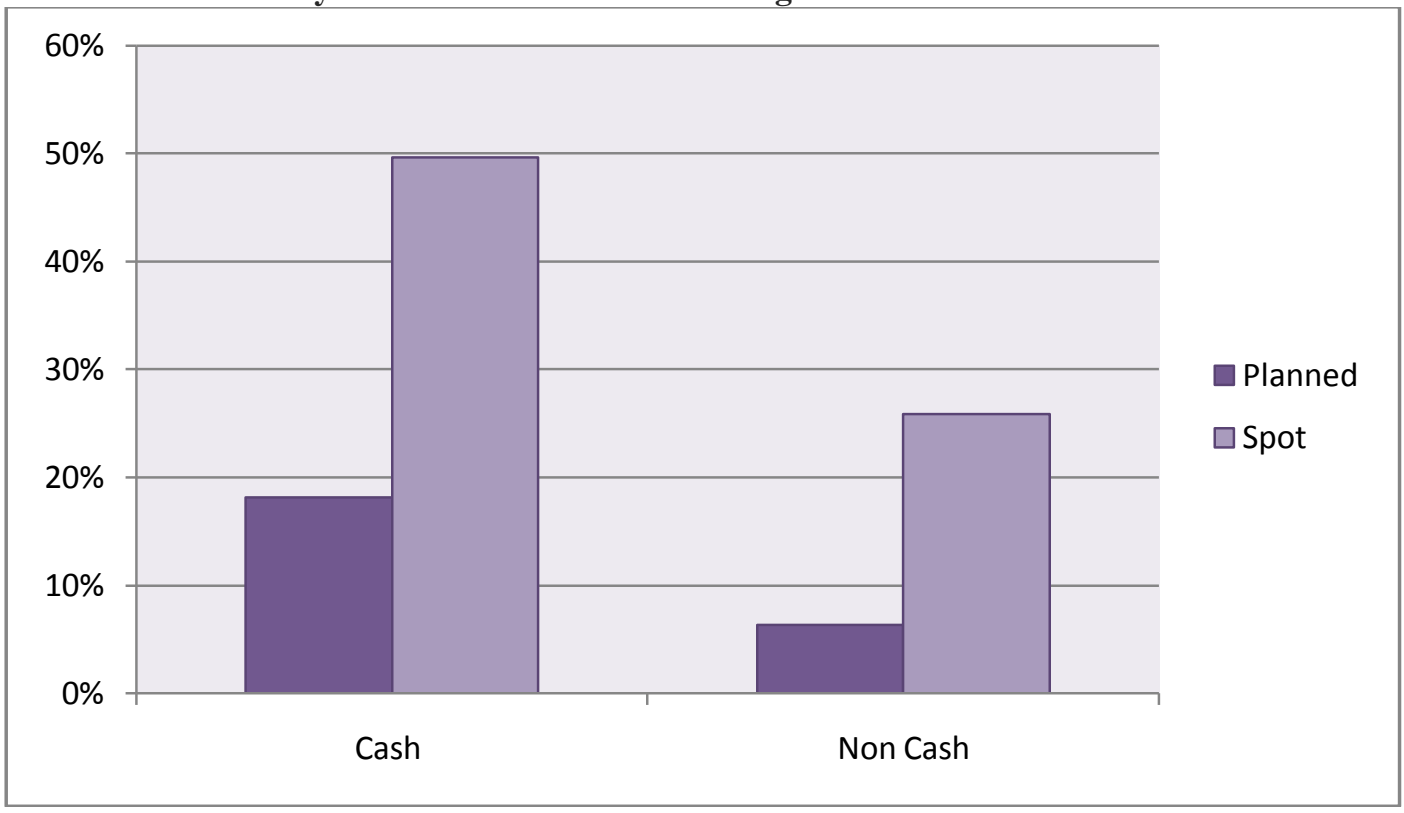

\section{Analysis:}

The delay in discharge process for patients whose mode of payment is by Cash -2 hours and 45 minutes The delay in discharge process for patients whose mode of payment is either insurance or credit -4 hours and 36minutes

The average time taken for discharge is compared between planned and spot discharge patients for Cash and Non Cash Patients.

Four important areas of analysis was consolidated from the entire discharge process and further analyzed. These four parameters that greatly influence the Discharge process are:

A. Time Taken for Bill Preparation

B. Time Taken for Bill Settlement

C. Time Taken for Handing over Final Discharge Summary

D. Time Taken for Patient to Vacate the Room

\section{Regression and Correlation Analysis:-}

Using SPSS software, the R-squared value was determined. The $\mathrm{R}$ - squared value determines the percentage significance of a factor in determining the overall time taken for the process. The delay in each step of the process was calculated. The regression correlation analysis was applied to identify the percentage significance in determining the overall delay in the discharge process.

Factors Attributing to Overall Time Taken and Delay in Discharge Process:-

\begin{tabular}{|l|l|r|r|}
\hline S. No & Steps in discharge process & $\begin{array}{l}\text { \% Significance in } \\
\text { determining overall time } \\
\text { taken for discharge } \\
\text { process }\end{array}$ & $\begin{array}{l}\text { \% Significance in } \\
\text { determining overall } \\
\text { delay in discharge } \\
\text { process }\end{array}$ \\
\hline A & Time taken for bill preparation & 33.56 & 30.3 \\
\hline B & Time taken for bill settlement & 15.9 & 17.7 \\
\hline C. & Time taken for Final Discharge Summary & 44.18 & 45.2 \\
\hline D. & Time taken for patient to vacate Room & 6.27 & 5.8 \\
\hline
\end{tabular}


From the results tabulated, the following can be determined:-

1. Time taken for bill preparation contributes $33.56 \%$ to the overall time taken and $30.3 \%$ to the delay in discharge process

2. This time involves:

- Time taken by the nursing staff to update the billing card.

- Time taken to send the billing card to the billing department.

- Time taken by the Billing department to update the final bill, which includes the bill received from pharmacy, radiology and laboratory investigations.

- The updated final bill which has to be notified to the patient relative.

3. Time taken for final discharge summary preparation contributes $44.18 \%$ to the overall time taken and $45.2 \%$ to the delay in discharge process.

4. This time includes:

- Time taken by the Jr. doctor to write an initial discharge summary,

- Time taken to send it to the typing pool and receive a typed copy of the rough summary.

- Time taken by the consultant or junior doctor to edit the rough summary.

- Time taken to type the fair summary.

- Time taken by the consultant or junior doctor to verify and sign the fair summary. The process is repeated until the fair summary is finally corrected.

\section{Reasons for Delay in Discharge Process:-}

As we have seen that the total discharge time is much more than the target so we have tried to find out the reasons for these delays. For that, we have tracked each patient who was going to be discharged and if there was some delay in discharge, we noted down the reason for that particular patient. At the end of the data collection we came to know that there are some assignable causes as well as chance causes for the delay. The following table shows the frequency of occurrence of the reasons of the delay in discharging:

TABLE: 6 - Bar Chart of Reasons for the Delay in Discharge:

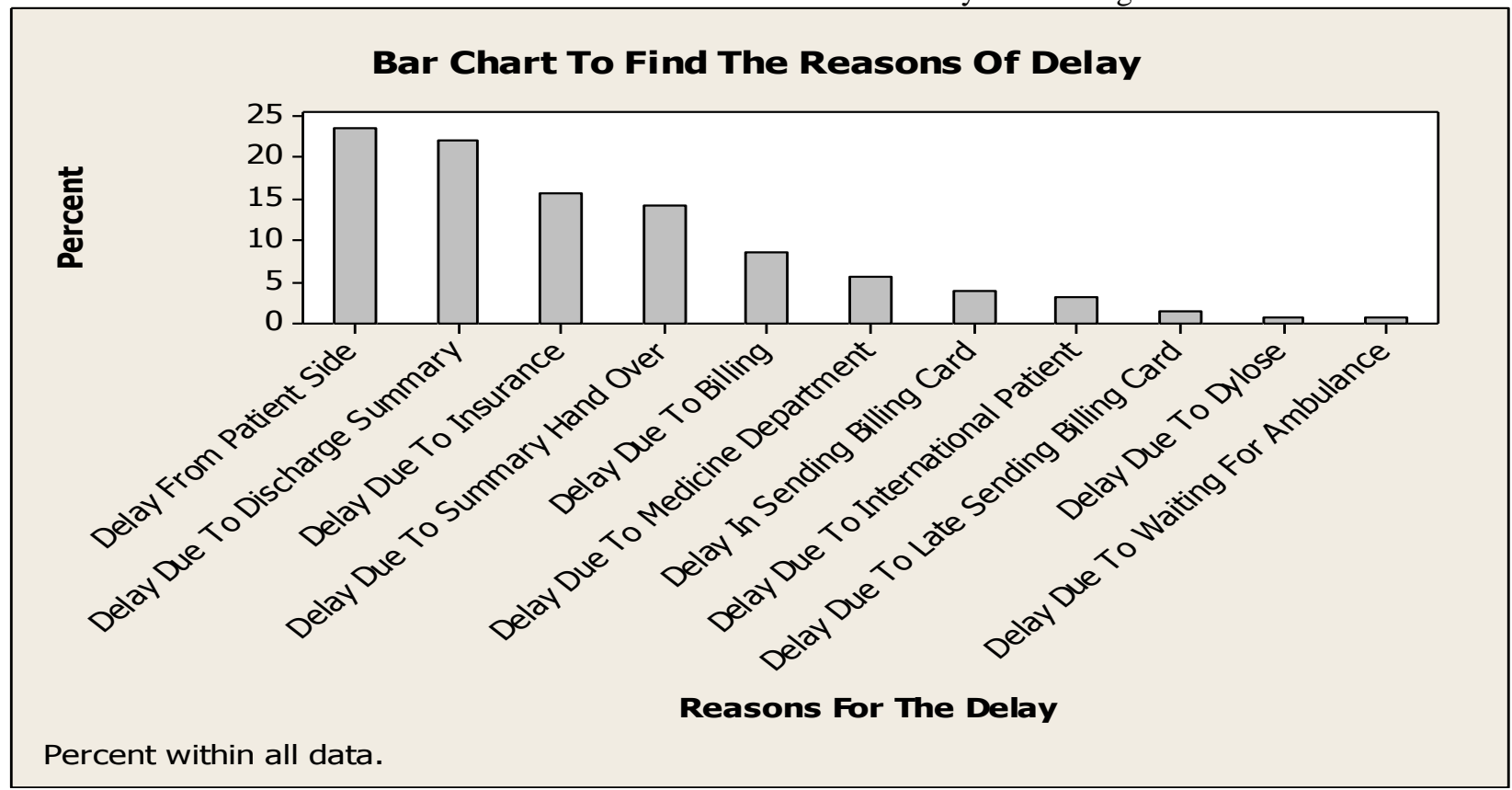

From the above figure we can see that there are many reasons for the delay. These are "Delay from patient side", "Delay due to discharge summary", "Delay due to late arrival of insurance approvals", "Delay due to late summary handover" etc. 
Cause and Effect Analysis:-

Fish Bone Diagram for Cause Analysis of Delay in Discharging Inpatient:-

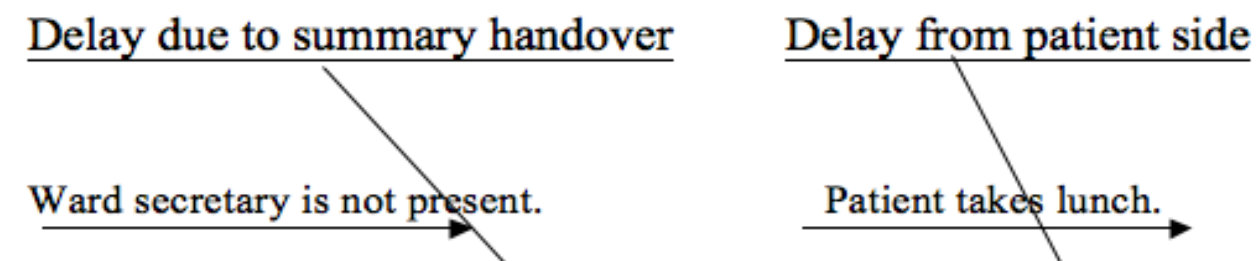

Nurse does not tell WS aboux discharge intimation. Patient waits for vehicle.

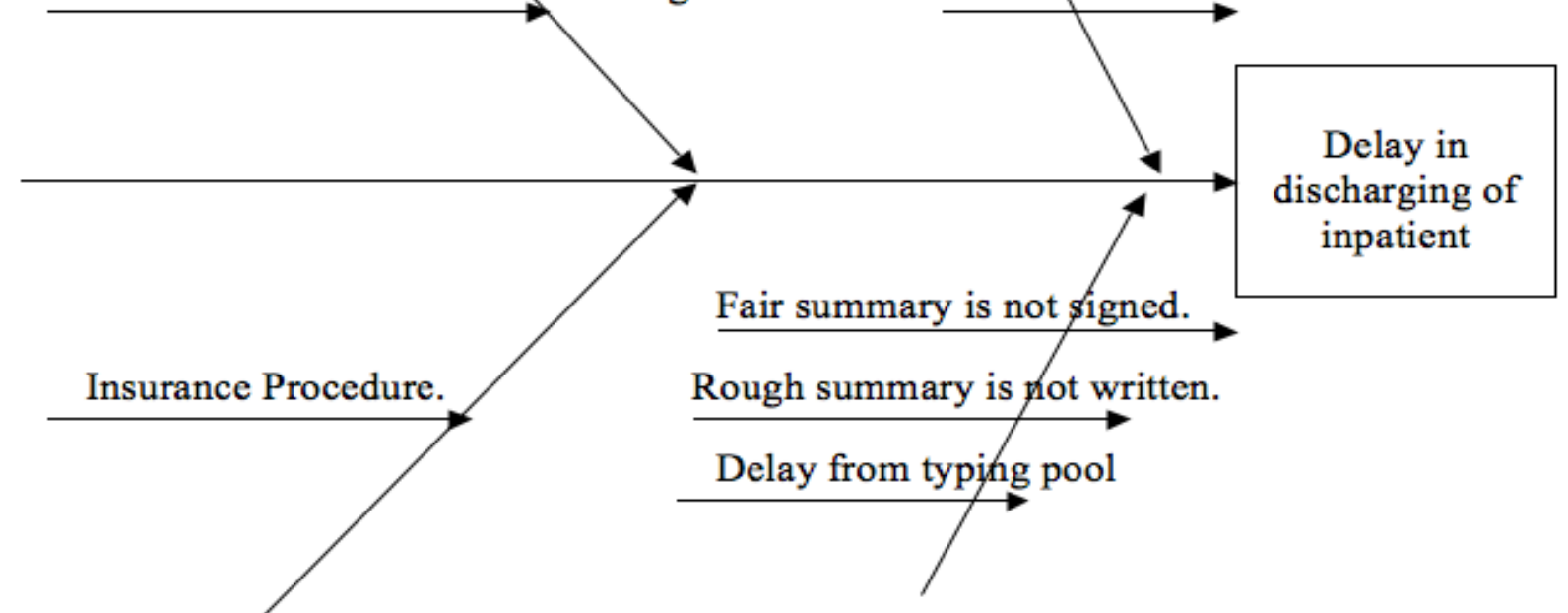

Delay due to insurance. $\quad$ Delay due to discharge summary.

\section{Recommendation and Concluding Remarks:- \\ Admission Process:}

- The entire system was found to be the same, as documented by the hospital. This assures that the staff follows the documented process and no deviation has been noted in the process, as defined by the management.

- Since maximum delay in admission process is caused due to the non - availability of bed, special attention should be focused on improving the bed management system and simultaneously the delay time for the discharged patients.

- Discharged but not vacated patients and stable discharged patients can be provided with a separate waiting area (discharge lounge) where they can wait until the discharge process is completed. Those beds could be arranged once the patient is shifted in the discharge lounge. Once the bill of the discharge patient is cleared and the patient is out from the system, immediately a fresh admission can be entered in the system and the new patient can be shifted to the ward.

\section{Discharge Process:-}

- The discharge process is an interdepartmental process and requires combine effort of all the departments, to achieve on timely discharges.

- There should be one Manager for each ward who will take care of the entire procedure for getting ready with the discharge summary. He should be able to approach any department either it is operation theatre or typing pool. If the consultant is in the operation theatre, he could go there and take the sign from the consultant. Sometimes it happens that the rough summary or fair summary is ready but due to unavailability of transport boy it is kept aside in the typing pool. So for every floor there should be one typist so that we can avoid the delay due to this transportation. 
- The insurance companies must be instructed to do their process in less time and there should be an upper limit of process time that if an insurance company crosses that line rapidly, its claim should not be accepted. If from a particular company we are getting more number of patients then the hospital should be linked with that company. If one patient of that particular company is getting admitted his process of payment should start immediately after the admission formalities of that patient is done.

- The time taken for the final bill preparation and final discharge summary are major contributors to the overall time taken for discharging a patient.

- Interim Bill must be adequately updated. Billing card system must be eliminated and system must be updated directly at the billing counter. Patients must be immediately intimated via an automatic SMS system. This can help to reduce the time taken by patient to settle the bill since the patient is settling most of the bill well ahead of the discharge date.

- Instruction in some form to vacate the room has to be given to the patient when everything required is submitted to him/her or when he/she is admitted. There is a "General Consent Form" in which instructions are given to patients regarding the rules \& regulations. In that form nothing is written about the discharge process. One sentence should be added in that form i.e., "Patient should leave the ward within one hour once everything is handed over to the patient or patient relative."

- Ward secretary should be instructed to advise the patient and patient relative about the importance of vacating the room. From the admission department, ard Secretary should be informed about the patient waiting for the bed. Repeated reminders from admissions would highlight the importance of discharged patient to vacate the room.

- The following simple form can be used to reduce the time taken in handing over the discharge summary to the patient

$$
\text { Today's Discharge Status: }
$$

Ward.

Date.

Sample Form for Discharge Status:

\begin{tabular}{|c|c|c|c|c|c|c|}
\hline Serial No. & Bed No. & IP No. & $\begin{array}{c}\text { Intimation } \\
\text { Given }\end{array}$ & $\begin{array}{c}\text { Summary } \\
\text { Ready }\end{array}$ & $\begin{array}{c}\text { Summary } \\
\text { Handed Over }\end{array}$ & $\begin{array}{c}\text { Patient } \\
\text { Vacated }\end{array}$ \\
\hline & & & & & & \\
\hline & & & & & & \\
\hline & & & & & & \\
\hline
\end{tabular}

Signature of Ward Secretary.

By introducing this form in each ward the process can be easily tracked. The ward secretary/nurse should be responsible for taking care of this format. They have to just mention the time on the particular box, whichever step is completed against each discharged patient. By applying this method we can easily tract the major delay areas.

The delays were mainly related to the process that can be improved if timely and effective initiatives are taken by the managers and other service providers. 


\section{References:-}

1. The essence of Hospital Management. - Joshua Khan

2. Joint Commission on Accreditation of Healthcare Organizations. (2004, February). New leadership standard on managing patient flow for hospitals: promoting more efficient patient movement. Joint Commission Perspectives, 24(1), 13-14.

3. Improving Inpatient Discharge Cycle Time and Patient Satisfaction by Todd Lammert, PT, Lean Sigma Black Belt - Columbus Regional Hospital Ian D. Wedgewood, PhD, Executive Director SBTI www. Sbtionline.com/files.CRH_HDCT_Case_StudyR1\%5B1\%5D

4. Apollo Hospital Admission Department Quality Manual.

5. Policies for reducing delayed discharge from hospital. Division of Health and Social Care, Faculty of Health and Medical Sciences, University of Surrey, Duke of Kent Building, Stag Hill, Guildford, Surrey GU2 7TE, UK. E-mail: k.bryan@ surrey.ac.uk

6. Glasby J, Littlechild R, Pryce K: Show me the way to go home: delayed hospital discharged and older people. 2004, Health Services Management Centre and Institute for Applied Social Sciences, University of Birmingham

7. Hammond CL, Pinnington LL, Phillips MF: A qualitative examination of inappropriate hospital admissions and lengths of stay. BMC Health Serv Res. 2009, 9: 44-10.1186/1472-6963-9-44.

8. Reasons for discharge delays in teaching hospitals. Revista de Saúde Pública, Print version ISSN 0034-8910, Rev. Saúde Pública vol.48 no.2 São Paulo Apr. 2014

9. What's the Holdup? Overcoming the Costly Delays in Admissions and Throughput. Written by Mark Hamm, CEO, EmCare Hospital Medicine | May 01, 2014

10. www.expresshealthcaremgmt.com

11. www.nicsl.com.au 